\title{
EL DERECHO A LA INFORMACIÓN CLASIFICADA EN EL MARCO JURÍDICO ESPAÑOL Y SU IMPACTO EN LOS DERECHOS DE LOS GRUPOS VULNERABLES: PROPUESTA PARA LA REFORMA DE LA LEY DE SECRETOS OFICIALES DE 1968
}

\section{THE RIGHT TO INFORMATION CLASSIFIED IN THE SPANISH LEGAL FRAMEWORK AND ITS IMPACT ON THE RIGHTS OF VULNERABLE GROUPS: PROPOSAL FOR THE REFORM OF THE OFFICIAL SECRETS ACT OF 1968}

\author{
$\mathrm{M}^{\mathrm{a}}$ Dolores MATEO ALCARAZ
}

\section{RESUMEN:}

La historia jurídica española más reciente, en cuanto al derecho de acceso a la información se refiere, se ve escrita por diferentes etapas en las que la censura y la falta de transparencia han formado parte de la vida amparándose, la comunidad política, en la premisa de la protección y la seguridad de la nación. La importancia de este hecho aumenta no sólo cuando se encuentra en desequilibrio la seguridad del Estado, si no cuando existe un grupo afectado que precisa de información referida a su salud.

Este artículo se propone desgranar el derecho a la información clasificada en el marco jurídico español y cómo diversos grupos vulnerables se pueden ver afectados si dicha información les está vetada así como la necesidad de anteponer el derecho a la información en materia de salud frente a la declaración de información clasificada que se pone a disposición de los intereses políticos con el fin de evitar un escandalo político.

\section{ABSTRACT:}

The most recent Spanish legal history, in terms of the right of access to information is referred to, is written by different stages in which censorship and lack of transparency have been part of life under cover, the political community, on the premise of the protection and security of the nation. The importance of this fact increases not only when the security of the State is imbalanced, but also when there is an affected group that needs information related to their health.

This article proposes describing the right to classified information in the Spanish legal framework and how various vulnerable groups can be affected if said information is vetoed, as well as the need to put the right to health information before the declaration. of classified information that is made available to political interests in order to avoid a political scandal.

\section{PALABRAS CLAVE:}

Derecho a la información, transparencia, censura, secretos de Estado, grupos vulnerables, derechos fundamentales

\section{KEYWORDS:}

Right to information, transparency, censorship, state secrets, vulnerable groups, fundamental rights 


\section{MARCO CONTEXTUAL DEL ACCESO A LA INFORMACIÓN EN ESPAÑA}

\section{De la dictadura a la democracia. La Ley para la Reforma Política}

La transición española supone un fuerte cambio a todos los niveles; aunque este paso de la dictadura a la democracia en un proceso gradual, no violento y basado en el acuerdo de las principales fuerzas políticas. El 5 de julio de 1976, Adolfo Suárez fue nombrado presidente del Gobierno por el rey Juan Carlos $\mathrm{I}^{1}$ A pesar de que tenía un perfil falangista, tenía también una actitud reformista y abierta al diálogo ${ }^{2}$. Esta decisión no fue muy aceptada por la población llegando incluso a causar rechazo por parte de algunos. Entre ellos destacan algunos de los ministros del gobierno anterior que se negaron a permanecer en el nuevo equipo como pueden ser Fraga, Areilza o Garrigues ${ }^{3}$. Con el nuevo presidente, todos los cambios negados durante la presidencia anterior, empezaron a llevarse a cabo. El Consejo de Ministros adelantó el paso a la democracia y consiguió en un año la amnistía para los presos políticos, una reforma constitucional y elecciones generales libres. En definitiva, podemos destacar a tres personas que encabezaron el proceso de la reforma política: el rey Juan Carlos, como Jefe de Estado, Torcuato Fernández Miranda como presidente de las Cortes y del Consejo del Reino y Adolfo Suárez como presidente del gobierno ${ }^{4}$. Como bien apunta CARLOS BARRERA (2004:889): "Desde el punto de vista político-constitucional, la Transición la hicieron, sobre todo, los reformistas del franquismo, que aportaron el peso decisivo para que la operación política llegase a buen puerto". A pesar de las dudas y recelos que ya hemos comentado que despertó el nuevo gobierno, éste propuso nuevas acciones convincentes que contribuyeron a que esos grupos que estaban descontentos con la designación cambiaran de parecer progresivamente. Entre esas nuevas propuestas destaca la supresión de instituciones como el Movimiento Nacional, la Organización Sindical o el Tribunal del Orden Público. Pero el paso más significativo fue cuando en septiembre de 1976, el Presidente de Gobierno anunció por televisión la propuesta de Ley para la Reforma Política. Ésta fue "la concreción legislativa del proceso de desmantelamiento del franquismo desde el propio régimen".5.

El Gobierno de Suárez destacó por la rapidez con la que elaboró el proyecto de reforma política y la habilidad que tuvo para dejar neutralizadas a las posibles oposiciones. ${ }^{6}$ Ese

1 El rey cuando se percató de que los debates en el Consejo Nacional se eternizaban y ponían de manifiesto sobre todo sus resistencias a desaparecer, llamó a Arias y le obligó a presentar la dimisión. El 1 de julio de 1976 los periódicos sacaron a la calle, a las 11 de la noche, ediciones especiales con la gran noticia sobre la dimisión (Tuñón, 1991:68).

2 Para ampliar ver (Tuñón, 1991:69)

3 "Si Arias caía víctima del bunker y si el rey se había comprometido con la democracia, la conclusión obvia era que el nuevo presidente sería alguna de las personalidades más notoriamente reformistas" (Tuñón, 1991:68). Pero al no ser así, la decisión sorprendió a la población y llegó a ser muy criticada.

4 Estas personas tenían un punto en común y era que los tres procedían del franquismo. El rey había sido designado por Franco como sucesor suyo al frente del país mientras que Fernández Miranda y Suárez habían desempeñados altos cargos durante el régimen franquista.

5 Así es como queda definida la Ley para la Reforma Política en: "La transición política. La Constitución de 1978 y el Estado de las Autonomías", www.historiasiglo20.org, fecha de consulta: 22 diciembre 2011. 6 "Ante todo, la reforma prevista tendría la ventaja de la simplicidad-. Se presentaría a las Cortes un proyecto de ley que consistiría básicamente en convocar elecciones para elegir dos cámaras, un Congreso y un Senado, por votación universal, directa y secreta." (Tuñón, 1991:68) 
proyecto de reforma política es "el instrumento jurídico-político que hizo posible el cambio, o lo que es lo mismo, alcanzar un régimen democrático desde la propia legalidad franquista vigente, que fue la Ley para la Reforma Política. Esta era una norma que, fundamentalmente, hacía posible la convocatoria de unas elecciones generales y la constitución de unas Cortes que se encargarían de realizar el resto de la reformas" (BARRERA, 2004:899).

A mediados del mes de octubre las Cortes aprobaron el texto de la Ley por una amplia mayoría. Este hecho hizo que se viera reforzada la posición tanto del rey como de gobierno, que recibieron un gran apoyo popular cuando, tras el Referéndum, el 15 de diciembre de 1976 fue definitivamente aprobada la Ley para la Reforma Política por el pueblo español con una participación del $77.7 \%$, siendo un $94.1 \%$ los votos afirmativos.

Dicho Referéndum constituye, junto con la victoria del gobierno, la derrota de la oposición que recordemos que estaba muy unida a comienzos de este mismo año. A pesar de ello, para la completa legitimación del proceso de cambio Suárez necesitaba la cooperación de la oposición ya que, de no ser así, no tendría credibilidad democrática. Finalmente la Reforma Política culmina con la aprobación de la Constitución Española en 1978, constituyendo al Estado Español como un "Estado social y democrático de Derecho" y da lugar a nuevas leyes e instituciones más cercanas al modelo europeo.

En este artículo vamos a centrar nuestra atención en el derecho a la información clasificada, cuestión a la que se dedican un artículo específico en la Carta Magna. Pero antes de comenzar con el análisis del derecho constitucional a la información, consideramos oportuno hacer una breve referencia al mismo en la época franquista para poder observar su evolución histórica. El periodo de la dictadura no suele ser incluido en las investigaciones de historia constitucional ya que desde su instauración hasta 1978 no existe un texto como tal. Como afirma JoAQuín URÍAs (2009:49): “ El Estado se organiza sin Constitución escrita. Se organiza basándose en relaciones de mera fuerza, poder alegal, pero también, progresivamente, a través de leyes"7.

\section{La Ley de Prensa de 1966. De la censura explícita a la censura encubierta}

Con la llegada de Fraga al ministerio de Información y Turismo en 1962, comienza un proceso liberalizador para la prensa, que fue beneficiosa para las publicaciones y, de paso para la publicidad. Como dice BARRERA (2008:1088): "Fraga llevó a cabo una política de concesiones liberalizadoras: autorización de nuevas publicaciones incluso no afines con el régimen, supresión casi total de consignas, suavización de la censura, celebración de ruedas de prensa, etc". Pero esta Ley no es tan liberalizadora como se hacía $v^{8}{ }^{8}$, sino que más bien se trataba de una censura encubierta, y queda definido el

\footnotetext{
7 Urías continúa afirmando que "por encima de estas leyes va a haber siempre un poder desvinculado y autónomo es indudable, pero también es cierto que la mayor parte del funcionamiento estatal se atuvo siempre a estas normas de que se iba dotando autónomamente" (2009:49).

8 La Ley 14/1966 nace de "la necesidad de adecuar aquellas normas jurídicas a las actuales aspiraciones de la comunidad española y a la situación de los tiempos presentes (...). Al emprender decididamente esta tarea, el Gobierno ha cumplido escrupulosamente su papel de fiel intérprete del sentir y del pensar del país, con el rigor y el estudio que deben ineludiblemente preceder a la reacción de todo texto legislativo que quiera nacer con una pretensión no sólo de viabiblidad, sino también de fijeza y de permanencia".
} 
derecho a la información a través de sus limitaciones. No hay una definición explícita del derecho a la información sino que la primera deviene de las limitaciones del último. Es cierto que supone un gran cambio para la prensa española y ya en el preámbulo habla de la libertad de expresión, elección de director y libertad de empresa, lo que supone un avance en lo que a libertades se refiere. Pero también es cierto que en el Artículo segundo de la Ley de Prensa e Imprenta de 1966 determina que son limitaciones: "El respeto a la verdad y a la moral: el acatamiento de la Ley de Principios del Movimiento ${ }^{9}$ y demás Leyes Fundamentales ${ }^{10}$; las exigencias de la defensa nacional, de la seguridad del Estado y del mantenimiento del orden público interior y la paz exterior". Es decir, que si no se hace un buen uso de las libertades - y cuando hablamos de buen uso se refiere a estar en la misma línea del régimen-, dichas libertades quedarán limitadas. Miguel Delibes lo expresa de esta forma: "Antes te obligaban a escribir lo que no sentías, ahora se conforman con prohibirte que escribas lo que sientes, algo hemos ganado" (SÁNCHEZ Y BARRERA, 1992: 411).

Podemos decir que el principal cambio que se produce con esta Ley en comparación con la de 1938 es lo que define como "consulta voluntaria". Una vez que se suprime la censura -salvo en los casos de Estado de Excepción- aparece la consulta voluntaria donde el director del medio de prensa podía ir a la Administración con el fin de que esta diera su visto bueno a la publicación o no; básicamente es un cambio de términos porque en al fin y al cabo, en el marco legal no se modifica nada. En 1967 se reforma el Código penal ${ }^{11}$ y define como delito el incumplimiento de las obligaciones del Artículo 2 de la Ley de Prensa e Imprenta y además, al año siguiente se aprueba la Ley de Secretos Oficiales, la cual será estudiada a lo largo de este artículo.

\footnotetext{
9 La Ley de Principios del Movimiento Nacional (1958) forma parte de las Leyes Fundamentales del franquismo. En una etapa de apertura del régimen pasado el período de postguerra, esta Ley constituye una reafirmación del los pilares del franquismo. Esta Ley estuvo vigente hasta la muerte del general y la llegada del nuevo Gobierno, con el Rey y Adolfo Suárez al frente, y la Ley para la Reforma Política de 1977.

${ }^{10}$ Junto con la Ley de Principios del Movimiento podemos encontrar seis más a las que conocen como las Leyes Fundamentales. El General Franco, con el interés de continuar con el franquismo se opuso a una posible Constitución -por asemejarse a la constitución que se instauró en la II República- y promulgó un conjunto de leyes que se iban conformando a medida que las necesidades del régimen variaban.

Entre estas leyes podemos encontrar: El Fuero del Trabajo (1938), la ley Constitutiva de las Cortes (1942), el Fuero de los Españoles (1945), la Ley de Referéndum (1945), la ley de Sucesión (1947), Ley de Principios del Movimiento Nacional (1958) y la Ley Orgánica del Estado -L.O.E.- (1966).

${ }^{11}$ El Articulo 165 bis b) del Código Penal, publicado en «BOE» núm. 86, de 11 de abril de 1967, se introduce por la ley 3/1967 de 8 de abril, y eleva a delito las acciones contras las Leyes Fundamentales: Artículo ciento sesenta y cinco bis b).

Serán castigados con las penas de arresto mayor y multa de cinco mil a cincuenta mil pesetas los que infringieren por medio de impresos las limitaciones impuestas por las leyes a la libertad de expresión y al derecho de difusión de información mediante la publicación de noticias falsas o informaciones peligrosas para la moral o las buenas costumbres; contrarias a las exigencias de la defensa nacional, de la seguridad del Estado y del mantenimiento del orden público interior y de la paz exterior, o que ataquen a los Principios del Movimiento Nacional o a las Leyes Fundamentales, falten al respeto debido a las instituciones y a las personas en la crítica de la acción política o administrativa, o atenten contra la independencia de los Tribunales.

Cuando los hechos revistieren a juicio del Tribunal gravedad manifiesta la pena aplicable será la de prisión menor y multa de diez mil a cien mil pesetas.
} 


\section{EL RÉGIMEN JURÍDICO GENERAL DEL DERECHO DE ACCESO A LA INFORMACIÓN CLASIFICADA EN ESPAÑA}

\section{La configuración del derecho a la información y su relación con los Secretos Oficiales}

Ante un panorama con nuevas Leyes aparentemente "aperturistas" pero a efectos prácticos igualmente sancionadoras, no será hasta 1978 con la llegada de la Constitución española cuando se empiece una verdadera etapa de libertad. En ella, aparece de nuevo una mención para el derecho a la información. Y, de la misma manera que en las leyes anteriores, queda definido por medio de sus límites de acceso a la información pero esos límites son menores y ya no se habla únicamente del acceso a la información sino a recibir y difundir información ${ }^{12}$. En el artículo 20.1 d) C.E. se desarrolla el derecho a la información en sus dos vertientes. La primera de ellas consiste en información activa, es decir, el derecho a difundir información; la segunda es la información pasiva o el derecho a recibir información. Ésta última faceta implica que cada individuo puede no solo elegir si desea recibir información o no, sino que también qué información desea recibir constituyéndose así en un derecho activo de la persona (VENTOSA, 1998).

Retomando la premisa de que el derecho a la información queda definido por sus limites de acceso, cabe mencionar que son dos los artículos constitucionales que hacen referencia a este hecho. En primer lugar, el art. $20.4 \mathrm{CE}^{13} \mathrm{y}$, en segundo lugar, el art. 105. b) de nuestra Constitución ${ }^{14}$. Este límite de acceso informativo tiene carácter constitucional y viene impuesto por nuestra norma y refleja la continuidad de la Ley de Secretos Oficiales de 1968, modificada por Ley de 1978. Al ser por tanto un límite con

\footnotetext{
${ }^{12}$ Artículo 20.
}

1. Se reconocen y protegen los derechos:

a) A expresar y difundir libremente los pensamientos, ideas y opiniones mediante la palabra, el escrito o cualquier otro medio de reproducción.

b) A la producción y creación literaria, artística, científica y técnica.

c) A la libertad de cátedra.

d) A comunicar o recibir libremente información veraz por cualquier medio de difusión. La Ley regulara el derecho a la cláusula de conciencia y al secreto profesional en el ejercicio de estas libertades.

2. El ejercicio de estos derechos no puede restringirse mediante ningún tipo de censura previa.

3. La Ley regulara la organización y el control parlamentario de los medios de comunicación social dependientes del Estado o de cualquier ente publico y garantizara el acceso a dichos medios de los grupos sociales y políticos significativos, respetando el pluralismo de la sociedad y de las diversas lenguas de España.

4. Estas libertades tienen su limite en el respeto a los derechos reconocidos en este Título, en los preceptos de las Leyes que lo desarrollan y, especialmente, en el derecho al honor, a la intimidad, a la propia imagen y a la protección de la juventud y de la infancia.

5. Solo podrá acordarse el secuestro de publicaciones, grabaciones y otros medios de información en virtud de resolución judicial.

\footnotetext{
13 «Estas libertades tienen su límite en el respeto a los derechos reconocidos en este título, en los preceptos de las leyes que lo desarrollen y, especialmente, en el derecho al honor, a la intimidad, a la propia imagen y a la protección de la juventud e infancia»

14 «La ley regulara: el acceso de los ciudadanos a los archivos y registros administrativos, salvo en lo que afecte a la seguridad y defensa del estado, la averiguación de los delitos y la intimidad de las personas».
} 
carácter constitucional, se le da al Estado la potestad de no hacer públicas determinadas informaciones que puedan poner en peligro la defensa y seguridad nacional. En este contexto, no existe más normativa en cuanto al acceso de materias clasificadas o secretas en el marco legislativo español a pesar de que ciertamente todas las leyes o normas que hacen referencia al acceso a la información tienen en cuenta los límites de acceso a la misma amparándose en los artículos citados supra.

La problemática de los límites de acceso a información clasificada o secreta son varios y de diferente índole. Es coherente que cuando se trata de un caso de seguridad nacional o de la defensa del Estado se tenga que limitar o el acceso a la información a un grupo reducido de personas pero, si un hecho en el que además de ello, se ve implicado la vulnerabilidad de la salud de un determinado grupo, entran en discusión dos cuestiones éticas ya que, si en un primer lugar sería necesario que, ante un hecho como puede ser la contaminación radiológica de Palomares ${ }^{15}$ (Almería) es preciso que en primera instancia se delimiten todas las informaciones relativas al incidente con el fin de preservar la seguridad nacional ${ }^{16}$, también es necesario que, una vez que la situación de peligro en la que pueda verse comprometida la seguridad queda controlada, también se debe tener en cuenta la cuestión radicalmente necesaria de la salud de los ciudadanos o del grupo que pueda verse implicado en el suceso.

\section{La aprobación de la ley 19/2013, de 9 de diciembre, de transparencia, acceso a la información pública y buen gobierno}

El principio de publicidad se constituye en la actualidad como la norma básica para la actividad diaria del Estado ya que cada vez la ciudadanía reclama saber cuáles son las actividades y decisiones del estado y cómo se llevan a cabo. Esta premisa constituye una herramienta para fortalecer el Estado de Derecho ya que se da lugar a una situación de apertura y de no opacidad que refuerza la confianza de la ciudadanía ya que las acciones del Estado no deben guiarse únicamente por lo expuesto en el ordenamiento jurídico sino también por una conducta ética que otorgue a los ciudadanos de la confianza en sus gobernantes. En este afán por demostrar la transparencia de la que goza en la actualidad el Gobierno y la comunidad política en general, se aprueba en 2013 la ley 19/2013, de 9 de diciembre, de transparencia, acceso a la información pública y buen gobierno.

Dicha ley no viene a aclarar nada sobre el acceso a materia clasificada ya que no se modifica en ningún momento nada de lo establecido con anterioridad. Por tanto, si bajo la premisa de preservar la seguridad del país que se recoge en la Ley $9 / 1968$, todas las sucesivas van a mantener los mismos presupuestos, entonces de nada sirve en cuanto a información clasificada se refiere, que exista una nueva ley de transparencia donde en

\footnotetext{
15 Se denomina "Caso Palomares" al accidente ocurrido en enero de 1966 en la localidad almeriense que le da nombre al caso. Tras la colisión de dos aviones estadounidenses en el espacio aéreo de Palomares, Cuatro bombas termonucleares transportadas por uno de ellos cayeron en dicha localidad -tres en tierra y una en el mar-. A pesar de que ninguna de las bombas estalló, si se que se produjo contaminación radiactiva en la zona del accidente junto con una nube de radiación que ocupaba más de 200 hectáreas y que conlleva a una situación el riesgo ambiental y para la salud que todavía no se ha solventado

${ }^{16}$ Art. 3 "Intereses fundamentales de la nación, la seguridad del Estado, la defensa nacional, la paz exterior o el orden constitucional».
} 

lolesmateo@gmail.com

esta cuestión sigue siendo opaca y hermética. Es por este motivo por el que considerar la mera existencia del secreto es una idea radicalmente contrapuesta con el principio democrático de publicidad.

La Ley 9/1968, de 5 de abril, de Secretos Oficiales pretende establecer un principio general de publicidad, teniendo únicamente como excepción caso de "materias clasificadas", pero realmente no existe un cauce formal por el que los particulares puedan ejercer un verdadero derecho de acceso a archivos y registros administrativos, este hecho hace, por tanto, que se pueda negar este derecho y se pone de manifiesto una situación de opacidad y secretismo. Otra de las deficiencias que se presenta en todas las leyes de las que se viene hablando a lo largo de este artículo y, principalmente, en la ley 19/2013, es que no existe ningún listado al que se pueda acceder de manera pública que recoja todas aquellas informaciones, sucesos o temas en general que están declarados materias clasificada en todos sus rangos. Esto hace que no se sepa que una información tiene vetado su acceso hasta que no se solicita a través de la plataforma habilitada para la ciudadanía a través de la cual se puede demandar cualquier información de interés sobre la actividad administrativa. Parece que en este sentido, se ha visto la necesidad de tener información sobre asuntos de interés para los ciudadanos -y más aún si existe riesgo para la salud- por lo que se ha presentado una propuesta para la modificación de la actual Ley 48/1978 de Secretos Oficiales.

\section{Proposición para la reforma de la Ley de Secretos Oficiales de 1968}

El Grupo Parlamentario Vasco (EAJ-PNV) presentó en septiembre de 2016 una proposición para la reforma de la LSO de 1968. Se trata de una reforma de mínimos, en la que posiblemente se toma como referencia la FOIA (freedom of information act) estadounidense en cuanto a la desclasificación automática, la cual pretende romper con el bloqueo de acceso a la información en materia de las actuaciones y decisiones de las administraciones públicas. Al igual que en el caso español, la situación de guerra que se vivía en todo el mundo dio lugar a la declaración indiscriminada de la mayoría de informaciones como secretas y, tras el paso del tiempo, esta tendencia más que una excepción se ha llegado a convertir en regla. Por este motivo se quiere tomar como ejemplo la FOIA la cual establece periodos de clasificación ${ }^{17}$ de la información que una vez transcurridos, dicha información debe hacerse pública. Uno de los cambios, si no el más importante, que se sostiene en la Proposición es la desclasificación automática. En la LSO de 1968 vigente, el sistema de desclasificación recoge unas actuaciones prácticamente iguales al de clasificación, es decir, que es necesario que sea el mismo órgano que declara la clasificación, el que la desclasifique. Este hecho hace que la desclasificación de documentos oficiales haya sido prácticamente nula.

En el caso español que ahora nos ocupa, una vez llegada la proposición al Congreso de lo Diputados, ningún grupo parlamentario rechaza esta cuestión, aunque sí que existen puntos de desacuerdo todos ellos lo matizan de formas diversas en cuanto al número de años que deben estar clasificadas las materias según su rango. Haciendo un breve recorrido por las enmiendas presentadas por los grupos parlamentarios, se encuentra en primer lugar las del Grupo Parlamentario Popular que siguen las líneas generales de la

\footnotetext{
${ }^{17}$ Los periodos de clasificación dependen directamente del grado de clasificación de la información: confidencial, secreto y alto secreto.
} 
normativa relativa a la protección de información clasificada al amparo de la LSO en vigor. Además, se propone desechar el concepto de "secretos oficiales" para dar paso a "información clasificada", pero, lo que realmente se puede presentar como novedad es que se acepta el principio de desclasificación automática por plazos que presentaba el PNV aunque, como ya adelantábamos, con grades diferencias en los años que ocupan esos plazos. En segundo lugar, las enmiendas presentadas por el Grupo Parlamentario Socialista siguen la orientación general dispuesta en la Proposición de Ley presentada por el PNV. El resto de Grupos parlamentarios ofrecen enmiendas poco concretas y menos ambiciosas.

\section{EL IMPACTO DE LA FORMUALACIÓN DE INFORMACIÓN CLASIFICADA EN LOS GRUPOS VULNERABLES: EL "CASO PALOMARES"}

\section{El Caso Palomares y sus afectados, un grupo vulnerable al que se le niega su derecho a la información en materia de salud}

El lunes 17 de enero de 1966 se produjo el accidente aéreo que marcará a España como uno de los puntos contaminados por plutonio más importantes de Europa. Dos aviones estadounidenses - uno de ellos trasportaba cuatro bombas termonucleares- colisionaron sobre el espacio aéreo de Palomares. La caída de las bombas -tres de ellas en tierra y una en mar- produjeron contaminación radiactiva en la zona del accidente. Lo interesante de este hecho es que nos encontramos ante un caso donde entra en juego el riesgo ambiental y para la salud que todavía no se ha solventado.

En el momento histórico del accidente -Guerra Fría-, EE.UU. mostró un especial interés en ocultar el contenido de las bombas y estableció un perímetro de seguridad por parte de las Fuerzas Americanas que coadyuvó a este obscurantismo. Durante varios días se procedió a la limpieza de parte de la tierra contaminada, la cual fue trasladada a Nuevo Méjico. Dicha retirada de tierra, tal y como se reconoce en diversos informes posteriores al accidente elaborados y publicados por el CIEMAT o CSN, no fue suficiente para alcanzar una reparación integral de la contaminación ocurrida. Este dato nos lleva a pensar sobre la importancia de que los habitantes de Palomares hayan vivido y sigan sufriendo las consecuencias derivadas de un suelo contaminado, que vulneraría, además de algunos derechos fundamentales, el derecho a un medio ambiente adecuado para el desarrollo de la personalidad reconocido al más alto nivel por el art. 45 de la CETéngase en cuenta que en dicho lugar se han seguido desarrollando actividades agrícolas, con el riesgo tanto ambiental como en materia de salud que ello conlleva.-

Existen diferentes informes que indican que sigue habiendo contaminación en la zona del accidente. Si bien es cierto que la mayoría afirma que no existe riesgo real, en la monografía del comité asesor "Palomares. En el camino de la normalización radiológica", publicada por el CNS afirma que: "El riesgo que se podría dar en Palomares es que las partículas contaminantes, que están de un modo estable adheridas a los suelos, puedan ser ingeridas o inhaladas por su transferencia a alimentos o al aire" (2013: 30). También en 2008 se hallaron dos zanjas en las que Estados Unidos había enterrado materia radioactiva que seguía emitiendo radiación y es en esa zona donde además un informe ucraniano localiza unos niveles de radiación que, según ellos afirman que es mayor que en Chernóvil. Como es de esperar la prensa, tanto nacional 
como internacional, se ha ido haciendo eco de todo lo que ha ido aconteciendo desde el mismo día del accidente cuando narraban lo que iba sucediendo en el lugar y gracias a los cuales podemos construir lo acontecido en el accidente de Palomares, ya que el momento político en el que se produjo el acceso a la información estaba muy limitado.

El debate sobre el control político de la información está presente en España cada vez con más fuerza, donde se afirma que los medios de comunicación son la herramienta por excelencia para que el poder político pueda llegar a controlar la información del país. Los gestores políticos centran su atención en los mensajes que difunden y de los que se hacen eco los medios de comunicación ya que su permanencia en el poder depende del clima social, el cual se ve influenciado por la información que reciben los ciudadanos. El caso Palomares es un claro ejemplo de ello. Desde que ocurrió el accidente, la información a la que tenían acceso los medios de comunicación y, por consiguiente la ciudadanía, era limitada y sesgada.

Haciendo un repaso por las noticias publicadas por uno de los diarios de tirada nacional con mayor repercusión -La Vanguardia- encontramos que desde que se produce el accidente el objetivo principal (y por supuesto lógico) es el de intentar no crear alarma social. Pero no sólo eso, sino que presentan a las Fuerzas americanas como unos grandes héroes que vienen a llevarse toda la tierra contaminada. Héroes a los que hay que aplaudir por su gran trabajo y responsabilidad. Era todo un acontecimiento que "los americanos" fueran a un pequeño pueblo de la costa almeriense con un gran despliegue de vehículos y tiendas de campaña. Los habitantes de Palomares no querían perder ese momento por lo que salieron a la calle a fotografiarse con los restos de las bombas, incluso algunos cogieron algunas piezas como recuerdo.

Por otro lado, el presidente de la Junta de Energía Nuclear declaró en una entrevista publicada en el diario La Vanguardia el día dos de marzo de 1966 que en Palomares no había contaminación, es más, "ni la hubo, ni podía haberla". Como ya hemos comentado, la prensa española no tardó en acostumbrarse al secretismo que intentaron imponer ambas partes implicadas, y sólo se publicaron noticias de carácter tranquilizador y en contra de la crítica de la prensa extranjera.

La agencia United International Press es la primera en informar el día después del accidente: "Estados Unidos pierde un artefacto nuclear". La noticia no tiene confirmación oficial por ninguno de los países implicados pero parece una información irrevocable ya que los periodistas de la zona observan a los soldados americanos equipados con aparatos para medir la radiación y ropa específica anti radiación. Como hemos comentado, el que en España existiera la censura, ayudó a los intereses del Gobierno estadounidense para que la información fuera limitada y favorable a los intereses del mismo.

Pasado un mes y medio desde el accidente, y con la bomba caída al mar perdida, las noticias seguían en la misma tesitura: la negación de radiactividad, la completa normalidad del pueblo de Palomares o el magnífico comportamiento de las Fuerzas Americanas con los habitantes del pueblo ${ }^{18}$. El gobierno franquista, a través de la Juna

\footnotetext{
${ }^{18}$ La sensación de incertidumbre que se vivía gracias a las publicaciones de los medios extranjeros seguía latente hasta que el Ministro de Información y Turismo, Manuel Fraga, se bañó junto al embajador norteamericano, Biddle Duke, en la zona del accidente antes de que fuera encontrada la cuarta bomba que
} 

lolesmateo@gmail.com

de Energía Nuclear (JEN) se firma un acuerdo con Estados Unidos para el traslado de los restos de la tierra contaminada en la zona donde cayeron las bombas. Este acuerdo se cumplió aunque no en su totalidad.

Una vez encontrada la bomba perdida que cayó al mar, los medios de comunicación fueron dejando de lado las publicaciones sobre el accidente de Palomares y la contaminación del lugar. Esto se puede deber a la censura que el país tenía impuesta pero, con la muerte de Franco, la reforma política y la Constitución Española, el marco del accidente no varió. Declarado Secreto de Estado, poca información existe relativa al caso. La prensa se hace eco el día del aniversario del baño de Fraga en las aguas de la costa almeriense pero no de la contaminación del lugar, ni de la importancia que este hecho tiene.

A mediados de los noventa, la burbuja inmobiliaria llega a Palomares y se pretende construir miles de viviendas; este hecho fuerza al Gobierno a no dejar de lado la situación de este pueblo. En 1996, las mediciones de radiación registradas en el aire y los cultivos comienzan a dar niveles de americio peligrosamente altos (el americio, la desintegración del plutonio, se dispersa con mayor facilidad). El Ciemat, en el año 2001, registra un nivel de radiación 20 veces superior al considerado aceptable para un suelo habitable y el CSN alertó de que remover la tierra contaminada era un riesgo para la salud. Por lo tanto, el plan de urbanismo previsto se suspendió y en la Ley de Acompañamiento de 2003, el Gobierno incluye la expropiación del terreno donde cayeron las bombas. Todos estos movimientos no se comunican públicamente. Finalmente, en un informe preliminar del Ciemat, admite que existe contaminación fuera de las zonas delimitadas que supera los límites establecidos y se procede de nuevo a restringir el uso del suelo.

Algunas plataformas activistas y afines a la causa como Greenpeace o Ecologistas en Acción, han sido las encargadas de difundir lo que estaba pasando en la tierra de Palomares. Desde 2004, que España decidió limpiar la zona, le exigió a la Secretaria de Estado, Hillary Clinton, que EE.UU. se hiciera cargo del coste de esa limpieza y desde entonces han sido constantes las largas a la petición española. Estas conversaciones han sido conocidas a través de Wikileaks, una organización sin ánimo de lucro que se ocupa de publicar documentos con información sensible y de interés público desde el anonimato y de la que los medios españoles se han hecho eco.

A uno meses del cincuenta aniversario del accidente los gobiernos de Estados Unidos y España se firma un nuevo acuerdo de descontaminación de la zona donde se reconoce por tanto que las actuaciones anteriores no han sido efectivas. Aún así, los datos sobre el riesgo que supone el hecho de que los habitantes de Palomares estén expuestos a una radiación continuada durante décadas sigue siendo secreto. Este último acuerdo firmado puede concebirse como una declaración de intenciones por arreglar la zona ya que no se han establecido plazos ni responsabilidades, tanto económicas como gubernamentales, por tanto se sigue manteniendo un discutible secreto sobre la información del accidente de Palomares frente al ideal de la protección efectiva de los administrados.

cayó en el mar como un gesto tranquilizador hacia los habitantes de Palomares. Esta es la imagen más trascendente del accidente y parece que desde que el entonces ministro se bañó, la contaminación desapareció. 


\section{CONCLUSIONES:}

DOI: http://dx.doi.org/10.12795/IESTSCIENTIA.2018.i02.07

Lo que puede quedar patente tras esta breve investigación es que existen límites a un derecho constitucional de los cuales Urías (2009: 186-187) hace distinción entre dos tipos de restricciones que puede sufrir un derecho constitucional: "restricciones verticales, operadas por una norma al regular el ejercicio del derecho, como fruto de las necesidades del orden público constitucional; y conflictos horizontales, en los que un derecho fundamental sufre limitaciones a causa de la necesidad de articular su existencia con la de otros derechos". En el caso que nos compete, se estaría hablando de un conflicto de carácter horizontal en el que un derecho fundamental como es el de la salud, se ve impedido por la limitación del derecho de acceso a la información.

Es cierto que la clasificación o la desclasificación de documentos no es una cuestión meramente política, es decir, que en la actualidad esta decisión pudiera ser tomada por los jueces o ser revisada por los mismos en el caso de que se vieran afectados de manera negativa y ellos mismos fueran los que alegasen su derecho a tutela judicial efectiva (ALONSO DE ANTONIO, 2015:227) A pesar de ello, en lo relativo al accidente de Palomares, Ecologistas en Acción presentó una demanda contra las autoridades españolas por 'desinterés e inactividad' frente a la contaminación presente en el lugar, pero no se ha presentado de manera formal o que haya desembocado en un proceso judicial ninguna solicitud para el acceso o la revelación de los informes y estudios que se han ido realizando a los habitantes de Palomares ${ }^{19}$.

Se destaca entonces que a pesar de todos los avances que ha habido a lo largo de las décadas tras el accidente en lo que a acceso a la información se refiere, no hayan sido suficientes ya que, al estar declarado como secreto, no se conoce el riesgo que deviene de la radiación continuada a lo largo de más de cincuenta años a los que los habitantes de Palomares están sometidos. Para que estos sucesos no ocurran y que la comunidad afectada por un incidente que puede poner en riesgo su salud no sufra las consecuencias de la limitación de acceso informativo, es necesario una correcta interpretación de dichos límites en los que, si bien es cierto que entran en juego diferentes intereses políticos, la seguridad nacional o, como en este caso del que se viene hablando, las relaciones internacionales, no se puede obviar que cuando quedan comprometidos derechos fundamentales como el de la salud, difícilmente puede quedar justificado la negación a la información relativa a este hecho.

\footnotetext{
${ }^{19}$ Se puede entender que no se hagan públicos de manera explícita los datos personales de cada persona objeto de estudio pero sí es necesario que salgan a la luz los resultados, de forma general, de los estudios que se vienen realizando a la población de Palomares tras el accidente hasta la actualidad. Ya no solo para saber si existen consecuencias importantes que puedan afectar a la salud de los lugareños, sino también para poder dispersar -en la medida de lo posible- toda duda sobre la contaminación de la zona y su repercusión para los habitantes así como para el resto de ciudadanos que compran y se alimentan con productos cosechados en la zona.
} 


\section{BIBLIOGRAFÍA}

BARRERA, C. (2004). Los medios de comunicación en España. Historia del periodismo universal. Barcelona, Ariel.

Barrera, C., (2004): “La Transición democrática (1975-1978)”, en Paredes, Javier, 2004: Historia contemporánea de España. Siglo XX. Barcelona: Ariel

Canel, M. J. (1999). Comunicación política. Técnicas y estrategias para la sociedad de la información. Madrid: Tecnos.

García-Olivares, A. (1993). Desarrollo de un modelo de resuspensión de suelos contaminados, aplicación al área de Palomares. Centro de Investigaciones Energéticas, Medioambientales y Tecnológicas, CIEMAT.

Martínez, J. U. (2009). Lecciones de Derecho de la Información. Tecnos.

PALOMARES. En el camino de la normalización radiológica. Monografía del Comité Asesor para la Información y Partcipación Pública, Consejo de Seguridad Nuclear $(\mathrm{CSN})$.

Salas, L. P. (2008). Sistema Judicial, secreto económico y secreto de Estado. Inteligencia y seguridad: Revista de análisis y prospectiva, (5), 91-122.

J. J. Sánchez Aranda, C. Barrera del Barrio, Historia del periodismo español desde sus orígenes hasta 1975, op. cit., pág. 411

Sinova, J. (1986). El Estado y la información en España. Revista de estudios politicos, (49), 137-164.

Urías J., “Lecciones de derecho de la información”, Tecnos, Madrid, 2009.

Ventosa, J. J. T. (1998). La regulación legal de los secretos oficiales. Anuario de la Facultad de Derecho, (16), 357-388.

Yáñez Díaz, C.: El derecho a la información medioambiental: el Convenio de Aarhus y el Derecho español. Revista de derecho urbanístico y medio ambiente, no 40, No 224 (2006)125-154

50 años del accidente de Palomares. El suceso, las consecuencias y la gestión de los residuos radiactivos, Enero, 2016, Greenpeace.

CSN: Programas de vigilancia radiológica ambiental específicos. Vigilancia radiológica en el entorno de Palomares. En: https://www.csn.es/programas-de- vigilanciaradiolocia-ambiental-especificos

Convenio de Aarhus, 1998

Convenio relativo a la ayuda para la mutua defensa entre los Estados Unidos de América y España, de 2 de octubre de 1953 (BOE-275) 
IUS ET SCIENTIA (ISSN 2444-8478) 2018, Vol. 4 nº 2, pp. 107-119

"El derecho a la información clasificada en el marco jurídico español y su impacto en los derechos de los grupos vulnerables: propuesta para la reforma de la Ley de secretos oficiales de 1968", Mª Dolores MATEO ALCARAZ, Universidad de Murcia, lolesmateo@gmail.com

Recibido: 19/10/2018. Aceptado: 03/12/2018

DOI: http://dx.doi.org/10.12795/IESTSCIENTIA.2018.i02.07

Colección de Normas de Seguridad del OIEA NoWS-G-3.1 sobre el Proceso de rehabilitación de zonas afectadas por actividades y accidentes pasados. Viena, 2009

Publicación 111 del International Commission on Radiological Protection (ICRP) de 4 de abril de 2011

United States. Commission on Protecting, \& Reducing Government Secrecy. (1997). Report of the Commission on Protecting and Reducing Government Secrecy: Pursuant to Public Law 236, 103rd Congress. Government Printing Office.

Ley de prensa de 22 de abril de 1938

Ley 25/1964, de 29 de abril, sobre energía nuclear (BOE-107)

Ley 14/1966, de 18 de marzo de Prensa e Imprenta (BOE-67)

Ley 38/1995, de 12 de diciembre, sobre el derecho de acceso a la información en materia de Medio Ambiente (BOE- 297)

Ley 19/2013, de 9 de diciembre, de transparencia, acceso a la información pública y buen gobierno (BOE-295)

Hemeroteca Digital Diario El País (1976-2016) Hemeroteca Digital Diario La Opinión (2008-2016) Hemeroteca Digital Diario La Vanguardia (1966-2016) Hemeroteca Digital Diario Le Monde (1966-2016) Hemeroteca Digital Diario The New York Times (1966-2016) 